\title{
Tracheostomy in Infants after Cardiac Surgery: Indications, Timing and Outcomes
}

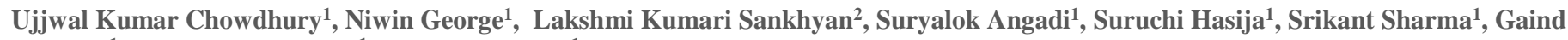
Saurabh ${ }^{1}$, Sai Divya Yadavalli ${ }^{1}$, Maroof A. Khan ${ }^{1}$

${ }^{1}$ Cardiothoracic Sciences Centre, All India Institute of Medical Sciences, New Delhi, India

${ }^{2}$ Department of Cardiothoracic and Vascular Surgery, All India Institute of Medical Sciences, Bilaspur, India

*Corresponding Author: Ujjwal Kumar Chowdhury, Professor Department of Cardiothoracic and Vascular Surgery AIIMS, New Delhi110029, INDIA.

Received Date: April 01, 2021; Accepted Date: May 12, 2021; Published Date: May 18, 2021

Citation: Ujjwal Kumar Chowdhury, Niwin George, Lakshmi Kumari Sankhyan, Suryalok Angadi, Suruchi Hasija, et al (2021) Tracheostomy in Infants after Cardiac Surgery: Indications, Timing and Outcomes. J. Clinical Cardiology and Cardiovascular Interventions, 4(10);

Doi: $10.31579 / 2641-0419 / 164$

Copyright: @ 2021 Ujjwal Kumar Chowdhury, This is an open-access article distributed under the terms of the Creative Commons Attribution License, which permits unrestricted use, distribution, and reproduction in any medium, provided the original author and source are credited.

\section{Abstract}

Objective: There is little consensus on the indications and optimal timing of tracheostomy in the pediatric population. Our primary aim was to determine if early tracheostomy improves patient outcomes (between $10^{\text {th }}$ and $15^{\text {th }}$ postoperative day).

Methods: A retrospective review of 84 neonates and infants requiring tracheostomy after cardiac surgery between January 1997 and December 2019 was performed. Indications and timings for tracheostomy, and risk factors for mortality were analyzed using Cox regression analysis. The receiver operating characteristic curve analysis, Youden's index, sensitivity and specificity plot were performed to determine the optimal cut-off point of the timing of tracheostomy.

Results: Twenty-five (29.76\%) neonates and 59 (70.23\%) infants with a median weight $7.6 \mathrm{~kg}$ (IQR: $3.1-9.25 \mathrm{~kg})$ were studied. Extubation failure and unsuccessful weaning from ventilator occurred in $45(53.6 \%)$ and $39(46.4 \%)$ patients respectively. The timing of tracheostomy of 15 days as the optimal cut-off point was associated with a sensitivity of $73 \%$ and a specificity of $84 \%$ and a Youden's index of 0.60 . Early tracheostomy was associated with decreased mortality $(p<0.001)$, morbidity $(p<0.001)$, decreased duration of ventilation $(p<0.001)$, ICU length of stay $(\mathrm{p}<0.001)$ and decreased time of decannulation $(\mathrm{p}<0.001)$.

The hazard of death was 5.26 times (95\% CI: 1.47-20.36) higher in patients undergoing late tracheostomy. At a median follow-up of 166 (IQR: 82.5-216) months, the actuarial survival was $86.61 \% \pm 0.04 \%$.

Conclusions: Early tracheostomy within $15^{\text {th }}$ postoperative day was associated with lower perioperative and late mortality, morbidity and ICU stay compared with tracheostomy between 15-30 days, and confers significant longterm advantages.

Key words: congenital heart disease; diaphragmatic paralysis; mechanical ventilation; outcome assessment; trachcheostomy; tracheobronchomalacia

Running head: Tracheostomy in infants

\section{Central Message}

Early tracheostomy between $10^{\text {th }}$ and $15^{\text {th }}$ postoperative day in infants is associated with lower perioperative and late mortality and improves patient outcomes.

\section{Perspective Statement}

Early tracheostomy between $10^{\text {th }}$ and $15^{\text {th }}$ postoperative day in infants avoids mediastinitis, minimizes subglottic stenosis, and is associated with lower mortality compared with late tracheostomy.

\section{Central Picture}

Legend: Results of tracheostomy in infant after cardiac surgery

\section{Abbreviations and Acronyms}

CHD

ECMO

oxygenation

ICU

IQR

LVEF
:Congenital heart diseases

:Extracorporeal membrane

:Intensive care unit :Interquartile range

:Left ventricular ejection fraction 


\section{Introduction}

Tracheostomy is performed in $1.3 \%$ to $2.7 \%$ of pediatric patients following cardiac surgery due mainly to requirement for prolonged mechanical ventilation and various other reasons. [1-9] Children requiring tracheostomy have a higher risk of adverse events and mortality secondary to their comorbidities. [1-9]

Tracheostomy in pediatric patients has been shown to reduce total mechanical ventilation time, shorten intensive care unit and hospital stays, decrease the occurrence of lower respiratory tract infection (LRTI), improve oral and dental hygiene, reduce in-hospital mortality and hospital cost. [1-16] In addition, it decreases the number of self extubations and extubation-reintubation cycles, requirement of sedation, upper airway injury including vocal cord ulceration, dead space ventilation, airway resistance, and work of breathing, therefore facilitating separation from ventilator support in a steady manner. [11-19]

Literature is divided on the definition of early and late tracheostomy. Although tracheostomy is conventionally considered in patients who are ventilator dependent 2 weeks after cardiac surgery, the definition of early tracheostomy in published investigations ranged between 48 hours to 63 days. [1-11,19]

In this study, postoperative day 15 were selected as the upper limit of early tracheostomy and day 30 as the lower limit for the late group, because the likelihood of successful extubation after 30 days of translaryngeal intubation in pediatric cardiac surgery is low and risks of tracheal airway complications increases thereafter. [2,8,12-19]

All patients undergoing tracheostomy between $10^{\text {th }}$ and $15^{\text {th }}$ postoperative days have been grouped under early tracheostomy, and all undergoing tracheostomy between $15^{\text {th }}$ and $30^{\text {th }}$ postoperative days have been grouped under late tracheostomy. In pediatrics, available data on pediatric tracheostomy are limited, and it is difficult to extrapolate data from other centers which practice prolonged mechanical ventilation. [1-19]

Although our institution is a tertiary level center, the socio-economic profile of the patients, and the lack of health insurance benefits in the developing world mandates reduction of duration of postoperative ventilation, and ICU stay, thereby attempting to reduce the cost of treatment. Tracheostomy if performed too early may be associated with increased risk of mediastinitis and if it is delayed, the number of extubation-reintubation cycle, risk of LRTI, and subglottic stenosis is increased. [11-19]

The primary objective of this study was to compare outcomes between early (within 15 days of primary operation) and late (between 15-30 days) tracheostomy. The secondary objectives were to: i) review the indications for tracheostomy in infants undergoing congenital heart surgeries requiring prolonged mechanical ventilation, and ii) evaluate the short- and long-term outcomes in terms of mortality and morbidity in these patients.

\section{Patients and Methods}

This retrospective study conforms to the principles outlined in the declaration of Helsinki and was approved by the Institutional Ethics Committee. Patients were enrolled in the study protocol after obtaining informed written consent from parents/guardians.

A 23-years (January 1997 to December 2019) retrospective review of medical records of all infants who underwent different types of closed and open heart surgical procedures (primary operation) at AIIMS, New Delhi, by the corresponding author, requiring prolonged postoperative ventilation $(n=3900)$ were studied, and patients who underwent tracheostomy $(n=84)$ postoperatively were identified and selected for further review. The six-monthly outpatient medical records were examined for follow-up data (Figure 1).

\section{Tracheostomy in Infants after Cardiac Surgery: Indications, Timing and Outcomes}

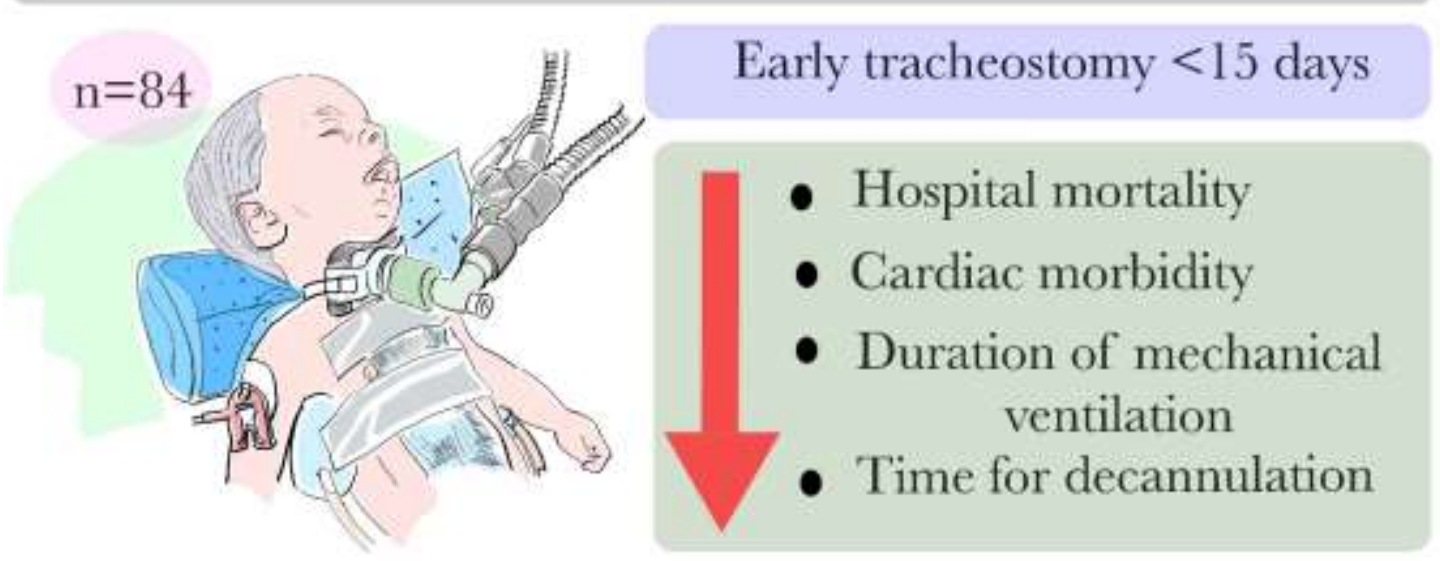

Figure 1: Graphic display $(n=84)$ showing postoperative outcomes of early tracheostomy in neonates and infants following cardiac surgery

\section{Criterions for selection of patients, indications and timings for tracheostomy}

Decisions for extubation, reintubation, and tracheostomy and decannulation were indeed made collectively by a panel of reviewers comprising of the cardiac intensivist, cardiac surgeon, respiratory therapist and otolaryngologist and remained uniform through the study period. The timing of tracheostomy was tightly linked to patient condition which in turn was linked to postoperative outcome.
Inclusion criteria: In this study on postoperative cardiac surgical patients, the decision/indications of tracheostomy were: i) those requiring prolonged mechanical ventilation following cardiac surgery due to multifactorial reasons, ii) those following failed extubation, and iii) those following second failed extubation. A combination of three of more concerning issues among postcardiac surgical patients requiring prolonged mechanical ventilation was present in more than half of patients in this study (Definitions, Tables 1-3). 


\begin{tabular}{|c|c|c|c|c|}
\hline S.No. & $\begin{array}{c}\text { Number } \\
\text { of } \\
\text { patients }\end{array}$ & Age at operation & Diagnosis & Operation \\
\hline 1. & 5 & $\begin{array}{l}9 \text { months, } 10 \\
\text { months, } 10 \text { months, } \\
10 \text { months, } 12 \\
\text { months }\end{array}$ & Symptomatic tetralogy of Fallot & Intracardiac repair \\
\hline 2. & 2 & 9 months, 10 months & $\begin{array}{l}\text { Tetralogy of Fallot, absent pulmonary } \\
\text { valve }\end{array}$ & Intracardiac repair \\
\hline 3. & 9 & $\begin{array}{l}2 \text { months, } 3 \text { months, } \\
31 / 2 \text { months, } 4 \\
\text { months, } 4 \text { months, } 6 \\
\text { months, } 8 \text { months, } 8 \\
\text { months, } 8 \text { months }\end{array}$ & $\begin{array}{l}\text { Tetralogy of Fallot with pulmonary } \\
\text { stenosis/hypoplastic pulmonary } \\
\text { arteries/atresia, univentricular heart } \\
\text { with pulmonary stenosis/atresia, } \\
\text { atrioventricular septal defect with } \\
\text { pulmonary atresia }\end{array}$ & $\begin{array}{l}\text { Right-sided modified Blalock- } \\
\text { Taussig's shunt/UKC shunt }\end{array}$ \\
\hline 4. & 1 & 5 months & $\begin{array}{l}\text { Severe pulmonary stenosis with atrial } \\
\text { septal defect }\end{array}$ & $\begin{array}{l}\text { Pulmonary valvotomy and atrial septal } \\
\text { defect closure (patch) }\end{array}$ \\
\hline 5. & 8 & $\begin{array}{l}1 \text { month, } 1 \text { month, } 2 \\
\text { months, } 2 \text { months, } 2 \\
\text { months } 1 \text { month, } 4 \\
\text { months, } 1 \text { month }\end{array}$ & $\begin{array}{l}\text { Tricuspid atresia/univentricular heart, } \\
\text { multiple ventricular septal } \\
\text { defect/unbalanced atrioventricular } \\
\text { septal defect with increased pulmonary } \\
\text { blood flow, failure to thrive, on } \\
\text { preoperative ventilation }\end{array}$ & Pulmonary artery banding \\
\hline 6. & 4 & $\begin{array}{l}9 \text { months, } 10 \\
\text { months, } 11 \text { months, } \\
11 \text { months }\end{array}$ & $\begin{array}{l}\text { Tricuspid atresia/univentricular heart } \\
\text { with pulmonary stenosis }\end{array}$ & $\begin{array}{l}\text { Bidirectional Glenn with anterior flow } \\
\text { open }\end{array}$ \\
\hline 7. & 3 & $\begin{array}{l}10 \text { months, } 11 \\
\text { months, } 11 \text { months }\end{array}$ & $\begin{array}{l}\text { Univentricular heart with excessive } \\
\text { pulmonary blood flow operation }\end{array}$ & $\begin{array}{l}\text { Bidirectional Glenn with pulmonary } \\
\text { artery banding }\end{array}$ \\
\hline 8. & 9 & $\begin{array}{l}20 \text { days, } 20 \text { days, } 12 \\
\text { days, } 19 \text { days, } 20 \\
\text { days, } 1 \text { month, } 18 \\
\text { days, } 19 \text { days, } 2 \\
\text { months }\end{array}$ & Transposition of the great arteries & Arterial switch operation \\
\hline 9. & 2 & 3 months, 5 months & $\begin{array}{l}\text { Transposition of the great arteries (late } \\
\text { presentation) }\end{array}$ & Senning's operation \\
\hline 10. & 1 & 2 months & Aortopulmonary window & Johanson's repair \\
\hline 11. & 2 & 2 months, 5 months & $\begin{array}{l}\text { Anomalous origin of left coronary } \\
\text { artery from pulmonary artery }\end{array}$ & Anatomical restoration \\
\hline 12. & 7 & $\begin{array}{l}31 / 2 \text { months, } 4 \\
\text { months, } 6 \text { months, } 8 \\
\text { months, } 8 \text { months, } \\
10 \text { months, } 11 \\
\text { months }\end{array}$ & $\begin{array}{l}\text { Ventricular septal defect (multiple } \\
\text { ventricular septal defect/prematurity/ } \\
\text { preoperative ventilation/malnutrition) }\end{array}$ & Ventricular septal defect closure \\
\hline 13. & 2 & 1 month, 1 month & $\begin{array}{l}\text { Coarctation of aorta with patent ductus } \\
\text { arteriosus }\end{array}$ & $\begin{array}{l}\text { Resection and end-to-end } \\
\text { anastomosis, division of patent ductus } \\
\text { arteriosus }\end{array}$ \\
\hline 14. & 3 & $\begin{array}{l}30 \text { days, } 35 \text { days, } 20 \\
\text { days }\end{array}$ & $\begin{array}{l}\text { Coarctation of aorta with ventricular } \\
\text { septal defect on ventilator }(2 \mathrm{~kg}, 2.5 \mathrm{~kg})\end{array}$ & $\begin{array}{l}\text { Pulmonary artery banding, repair of } \\
\text { coarctation }\end{array}$ \\
\hline 15. & 1 & 2 months & Interrupted aortic arch & Restoration of aorta \\
\hline 16. & 2 & 9 months, 11 months & $\begin{array}{l}\text { Previous pulmonary artery band due to } \\
\text { multiple muscular ventricular septal } \\
\text { defects }\end{array}$ & $\begin{array}{l}\text { Debanding pulmonary artery, VSD } \\
\text { closure, pulmonary arterioplasty }\end{array}$ \\
\hline 17. & 2 & 2 months, 3 months & Atrioventricular septal defect & Two-patch repair \\
\hline 18. & 3 & $\begin{array}{l}3 \text { months, } 5 \text { months, } \\
6 \text { months }\end{array}$ & $\begin{array}{l}\text { Heterotaxy with univentricular heart, } \\
\text { pulmonary stenosis, decreased } \\
\text { pulmonary blood flow }\end{array}$ & Bidirectional Glenn \\
\hline 19. & 3 & $\begin{array}{l}20 \text { days, } 1 \text { month, } 1 \\
\text { month }\end{array}$ & $\begin{array}{l}\text { Heterotaxy with totally anomalous } \\
\text { pulmonary venous connection }\end{array}$ & $\begin{array}{l}\text { Rechanneling of totally anomalous } \\
\text { pulmonary venous connection }\end{array}$ \\
\hline 20. & 3 & $\begin{array}{l}5 \text { days, } 15 \text { days, } 7 \\
\text { days }\end{array}$ & $\begin{array}{l}\text { Totally anomalous pulmonary venous } \\
\text { connection (infracardiac) on } \\
\text { preoperative ventilator }\end{array}$ & $\begin{array}{l}\text { Rechanneling of totally anomalous } \\
\text { pulmonary venous connection }\end{array}$ \\
\hline
\end{tabular}




\begin{tabular}{|l|l|l|l|l|}
\hline 21. & 8 & $\begin{array}{l}\text { 39 days, 2 months, 2 } \\
\text { months, 3 months, 3 } \\
\text { months, 3 months, 5 } \\
\text { months, 9 months }\end{array}$ & $\begin{array}{l}\text { Totally anomalous pulmonary venous } \\
\text { connection (supracardiac) }\end{array}$ & $\begin{array}{l}\text { Rechanneling of totally anomalous } \\
\text { pulmonary venous connection }\end{array}$ \\
\hline 22. & 4 & $\begin{array}{l}\text { 1 month, 2 months, } \\
2 \text { months, 1 month }\end{array}$ & $\begin{array}{l}\text { Mixed totally anomalous pulmonary } \\
\text { venous connection }\end{array}$ & $\begin{array}{l}\text { Rechanneling of totally anomalous } \\
\text { pulmonary venous connection }\end{array}$ \\
\hline
\end{tabular}

Table 1: Age at primary operation, diagnosis, type of operation of all patients in the study group undergoing tracheostomy $(n=84)$

\begin{tabular}{|c|c|}
\hline Variables & Number $(\%)$ \\
\hline \multicolumn{2}{|l|}{ Number of infants } \\
\hline$-\quad \leq 1$ month & $25(29.8 \%)$ \\
\hline$-\quad>1$ month & $59(70.2 \%)$ \\
\hline Age at operation (days), mean \pm SD & $\begin{array}{c}145.5 \pm 11.8 \\
\text { (median: } 4 \\
\text { months; IQR: } \\
23 \text { days-9 } \\
\text { months) }\end{array}$ \\
\hline Gestational age (weeks) & $36.2(29.7-37)$ \\
\hline Prematurity $<37$ weeks & $30(35.7 \%)$ \\
\hline Sex - Male & $50(59.5 \%)$ \\
\hline Birth weight $(\mathrm{kg})$ & $\begin{array}{c}\text { Median } 7.6 \mathrm{~kg} \\
\text { (IQR: } 3.1-9.25 \\
\mathrm{~kg} \text { ) } \\
\end{array}$ \\
\hline Low birth weight & $39(46.4 \%)$ \\
\hline Preoperative ventilation (days) & $29(34.5 \%)$ \\
\hline Genetic syndromes & $10(11.9 \%)$ \\
\hline Preoperative lung infection/lobar collapse & $19(22.6 \%)$ \\
\hline Upper airway problems & $16(19 \%)$ \\
\hline Unstable hemodynamics (on preoperative inotropes) & $39(46.4 \%)$ \\
\hline Non-cardiac comorbidities & $6(7.7 \%)$ \\
\hline Preoperative central neurological event & $5(5.9 \%)$ \\
\hline Preoperative sepsis & $19(22.6 \%)$ \\
\hline Unilateral diaphragmatic paralysis & $7(8.3 \%)$ \\
\hline Type of operation & \\
\hline - Intracardiac repair of tetralogy of Fallot & $7(8.3 \%)$ \\
\hline - Ventricular septal defect- isolated or associated anomalies & $9(10.7 \%)$ \\
\hline - Transposition of the great arteries & $11(13.0 \%)$ \\
\hline - Totally anomalous pulmonary venous connection & $18(21.4 \%)$ \\
\hline - $\quad$ Pulmonary stenosis with atrial septal defect & $1(1.1 \%)$ \\
\hline - $\quad$ Aortopulmonary window/ ALCAPA & $3(3.5 \%)$ \\
\hline - $\quad$ Atrioventricular septal defect (2 patch repair) & $2(2.3 \%)$ \\
\hline - Interrupted aortic arch & $1(1.1 \%)$ \\
\hline \multicolumn{2}{|l|}{ Closed heart procedures } \\
\hline - $\quad$ Systemic-pulmonary artery shunt & $9(10.7 \%)$ \\
\hline - $\quad$ Pulmonary artery banding & $10(8.4 \%)$ \\
\hline - Coarctation of the aorta & $2(2.3 \%)$ \\
\hline - $\quad$ Superior cavopulmonary anastomosis & $7(8.3 \%)$ \\
\hline - $\quad$ Superior cavopulmonary anastomosis + Pulmonary artery banding & $3(3.5 \%)$ \\
\hline \multicolumn{2}{|l|}{ Timing of tracheostomy } \\
\hline - By $10^{\text {th }}$ postoperative day & $23(27.3 \%)$ \\
\hline - Within $15^{\text {th }}$ postoperative day & $41(48.8 \%)$ \\
\hline - Within $30^{\text {th }}$ postoperative day & $20(23.8 \%)$ \\
\hline Total number of days intubated and ventilated prior to tracheostomy & 7 days-26 days \\
\hline Duration of ventilation after tracheostomy & 14 days-69 days \\
\hline Successful decannulation & $73(86.9 \%)$ \\
\hline Post tracheostomy cumulative mortality & $11(13.1 \%)$ \\
\hline Cardiopulmonary bypass time (minutes), mean \pm SD (range) & $\begin{array}{c}102.26 \pm 28.46 \\
(76-118)\end{array}$ \\
\hline Aortic cross-clamp time (minutes), mean \pm SD (range) & $\begin{array}{c}50.26 \pm 12.48 \\
(45-60)\end{array}$ \\
\hline Use of cardiopulmonary bypass & $63(75 \%)$ \\
\hline
\end{tabular}




\begin{tabular}{|l|c|}
\hline Variables & Number (\%) \\
\hline Hospital death & $9(10.7 \%)$ \\
\hline Late death & $2(2.7 \%)$ \\
\hline Lost to follow-up & $1(1.4 \%)$ \\
\hline Number of patients followed-up & $72(98.6 \%)$ \\
\hline
\end{tabular}

Table 2: Demographics of the patients in the study population $(n=84)$

\begin{tabular}{|c|c|}
\hline Postoperative issues & No. $(\%)$ \\
\hline Cardiac (Congestive heart failure, poor biventricular function, unstable hemodynamics) & $35(41.66 \%)$ \\
\hline Cardiac cachexia, low body mass, malnourishment, unstable hemodynamics (preoperative) & $39(46.4 \%)$ \\
\hline Persistent lobar collapse, pulmonary infection, sepsis (pretracheostomy) & $19(22.6 \%)$ \\
\hline Severe pulmonary artery hypertension (cardiac related) & $39(46.4 \%)$ \\
\hline Renal failure requiring peritoneal dialysis (pretracheostomy) & $17(20.2 \%)$ \\
\hline Unilateral diaphragmatic paralysis & $6(7.1 \%)$ \\
\hline Preoperative neurological event (Hypoxic, hydrocephalus) & $5(5.9 \%)$ \\
\hline $\begin{array}{l}\text { Postoperative new onset neurological event (Hypoxic, intracerebral bleed, subdural } \\
\text { hematoma) }\end{array}$ & $8(8.3 \%)$ \\
\hline Craniofacial syndromes and upper airway problems, glossoptosis & $10(11.9 \%)$ \\
\hline Excessive pulmonary secretions (pretracheostomy) & $37(44 \%)$ \\
\hline Chylothorax requiring surgical intervention & $4(4.7 \%)$ \\
\hline Postoperative extracorporeal membrane oxygenation & $3(3.6 \%)$ \\
\hline Subglottic stenosis & $3(3.6 \%)$ \\
\hline Tracheobronchomalacia & $3(3.6 \%)$ \\
\hline Cardiac + Renal & $36(42.8 \%)$ \\
\hline Cardiac and subglottic stenosis & $13(15.5 \%)$ \\
\hline Cardiac + Tracheobronchomalacia + suprastomal collapse & $13(15.5 \%)$ \\
\hline Cardiac + Diaphragmatic paralysis & $14(16.6 \%)$ \\
\hline Cardiac + Neurological event & $30(35.7 \%)$ \\
\hline 3 or more of $(1-11)$ & $49(58.3 \%)$ \\
\hline
\end{tabular}

Table 3: Reasons for prolonged ventilation of all patients in the study group undergoing tracheostomy $(n=84)$

Exclusion criteria: Infants with tracheostomy preoperatively, and those requiring prolonged mechanical ventilation but not tracheostomized were excluded. Due to variable surgical and postcardiac surgical practices, patients operated by other surgeons were excluded.

Tracheostomy was performed in the operating room using the open technique in all patients. Postoperative day 15 was selected as the upper

limit for early tracheostomy based on the evidences available in the literature, and an increased incidence of postoperative sepsis in the developing world, and to decrease the hospital cost. [1-11] Day 30 was selected as the lower limit for the late group in this study.

\section{Data collection}

In addition to baseline characteristics, intraoperative and postoperative findings (table 1), the following mechanical ventilation-related parameters were recorded: i) duration of respiratory support before surgery, ii) the duration of ventilation before tracheostomy, iii) the duration of ventilation after tracheostomy, and iv) time interval between tracheostomy and decannulation or death. The number of attempts at extubation, timing of decannulation (failed or successful), recannulation of tracheostomy, patient's outcome (decannulation/death) were noted for each patient. The indication(s) for tracheostomy, complications of tracheostomy, decannulation, and their outcomes were also recorded. [20]

Patients were classified with an airway anomaly if they had any major upper airway or laryngotracheobronchial abnormality confirmed by an otolaryngologist, using bedside bronchoscopy and laryngoscopy when clinically suspected. All tracheostomy were done surgically in operation room. Snuggly fitting tracheostomy tube with inflatable cuff was preferred on insertion and later changed to uncuffed tube after one week.

Decannulation was considered when patients had: i) stable hemodynamics with reduced/nil requirement of inotropes; ii) no requirement of ventilator support for a period of 7 days; iii) minimal requirement for suctioning; iv) no pulmonary atelectasis/lobar collapse vi) no diaphragmatic paresis/paralysis; vi) normal kidney function; vii) 
patent upper airway, ascertained with laryngoscopy vii) removal of any obstructing suprastomal granulation tissue; and viii) no comorbidities necessitating tracheostomy.

\section{Definitions}

Primary operation: In this study, we have used the term "primary" operation or procedure to refer to cardiac operation necessitating the period of postoperative ventilation leading to tracheostomy.

Outcome measures: Operative mortality (all cause) was defined as death either in ICU or prior to hospital discharge or within 30 days of the date of surgery according to the congenital heart surgery outcome measures endorsed by the Society of Thoracic Surgeons. [20] Short-term survival was defined as survival to hospital discharge. Long-term survival was defined as survival to most recent follow-up. Intubation time was defined as time in hours from the time of intubation either in the preoperative period or on the day of surgery to discontinuation of mechanical ventilation. Records were reviewed to determine whether patients had been successfully decannulated and if so, to document the time from the date of tracheostomy to decannulation, the length of stay in intensive care unit after surgery, and the need for surgical reintervention, when required.

Extubation failure: Extubation failure was defined as reintubation within 48 hours after extubation. For patients who failed extubation, reintubation was determined according to the following criteria: (i) hemodynamic instability; (ii) respiratory dysfunction (significant hypoxia, worsening hypercarbia, significant respiratory effort, respiratory fatigue, and massive atelectasis); (iii) airway obstruction; (iv) deteriorating level of consciousness; (v) major bleeding; and (vi) cardiac arrest. The decisions for extubation and reintubation were made by attending intensivist, cardiac surgeon and cardiac anaesthetist.

Suboptimal hemodynamics/low cardiac output syndrome: Suboptimal hemodynamic state/low cardiac output syndrome was defined as moderate or severe ventricular dysfunction requiring inotropic support (dopamine at $4-10 \mu \mathrm{g} /[\mathrm{kg} / \mathrm{min}]$ ), dobutamine at $5-10 \mu \mathrm{g} /[\mathrm{kg} / \mathrm{min}]$, epinephrine at $0.01-0.1 \mu \mathrm{g} /[\mathrm{kg} / \mathrm{min}]$, milrinone at $50 \mu \mathrm{g} / \mathrm{kg}$ intravenous bolus followed by $0.375-0.75 \mu \mathrm{g} /[\mathrm{kg} / \mathrm{min}])$, either isolated or in combination with or without mechanical circulatory assistance in the operating room or in the intensive care unit, to maintain stable hemodynamics in the absence of residual structural lesions and mechanical external compression after correction of all electrolytes or blood gas abnormalities and after adjustment of the preload to its optimal value. Low-output syndrome was also diagnosed if there was an increasing requirement of the previously mentioned inotropes along with afterload reduction with sodium nitroprusside.

Tracheostomy-related complications: Early complications were defined as those occurring within the first postoperative week. At one week, the tracheostomy has usually matured, and the first tube change is performed. Late complications were defined as those occurring after the first $1^{\text {st }}$ week.

Morbidities: Cardiac morbidity was defined as low cardiac output state with or without the requirement for extracorporeal membrane oxygenation. Renal morbidity was defined as oliguria $(<0.5 \mathrm{ml} / \mathrm{kg} / \mathrm{hr})$ or anuria with rising blood urea and serum creatinine and/or starting hemodialysis or peritoneal dialysis. Culture proven pneumonia, mediastinitis, wound infection and bacteremia were diagnosed by clinical findings and microbiological cultures, and lab results.

\section{Statistical Analysis}

Statistical analysis was performed using STATA 14.0 Software (College Station, Texas, USA). Continuous and interval-related data were presented as mean $\pm \mathrm{SD}$ or median (minimum-maximum), whereas categorical variables were presented as frequency distribution and percentages. Qualitative data were analysed by using $\square^{2} /$ Fisher's exact test to establish the association.

The receiver operating characteristic curve analysis was performed on the timing of tracheostomy and mortality to establish the cut-off point (days) for the early and late tracheostomy (Figure 2).

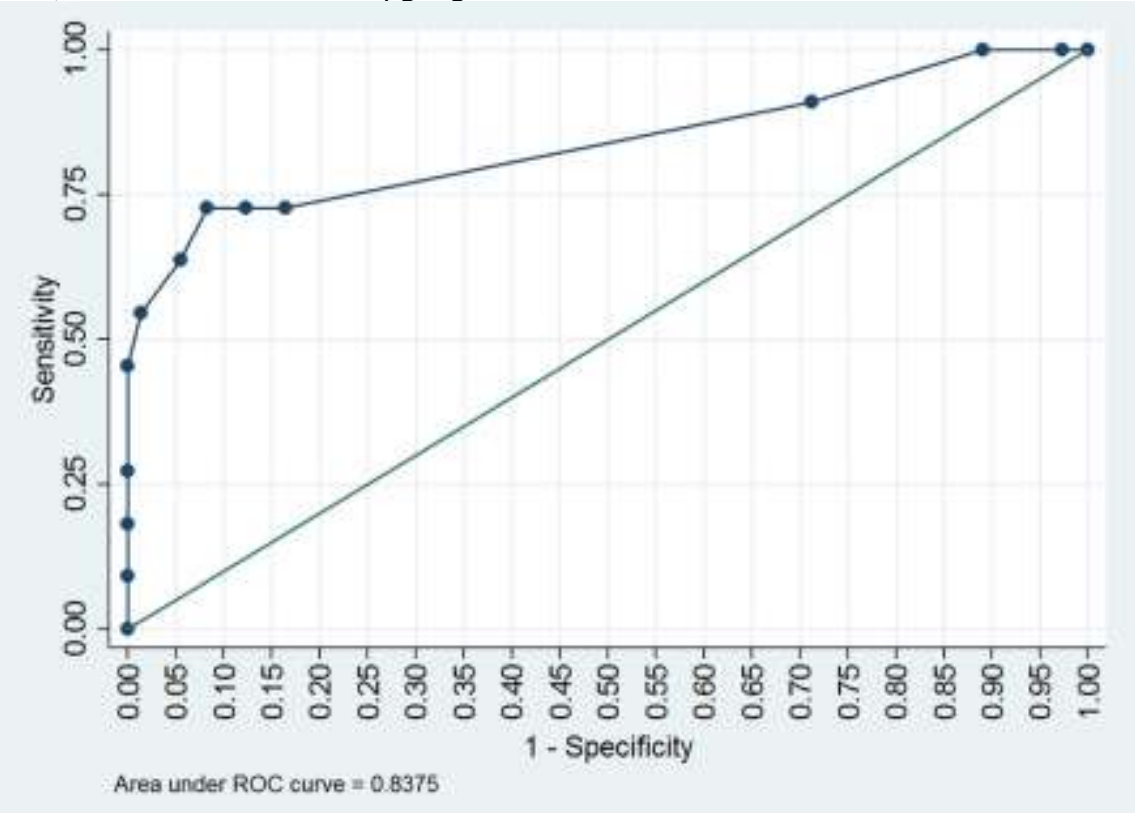

Figure 2: The receiver operating characteristic curve (ROC) of patients undergoing early and late tracheostomy following congenital heart surgeries in this study. 
Youden's index was calculated to determine the optimal cut-off point of the timing of tracheostomy, which was also represented by a sensitivity and specificity plot (Figure 3).

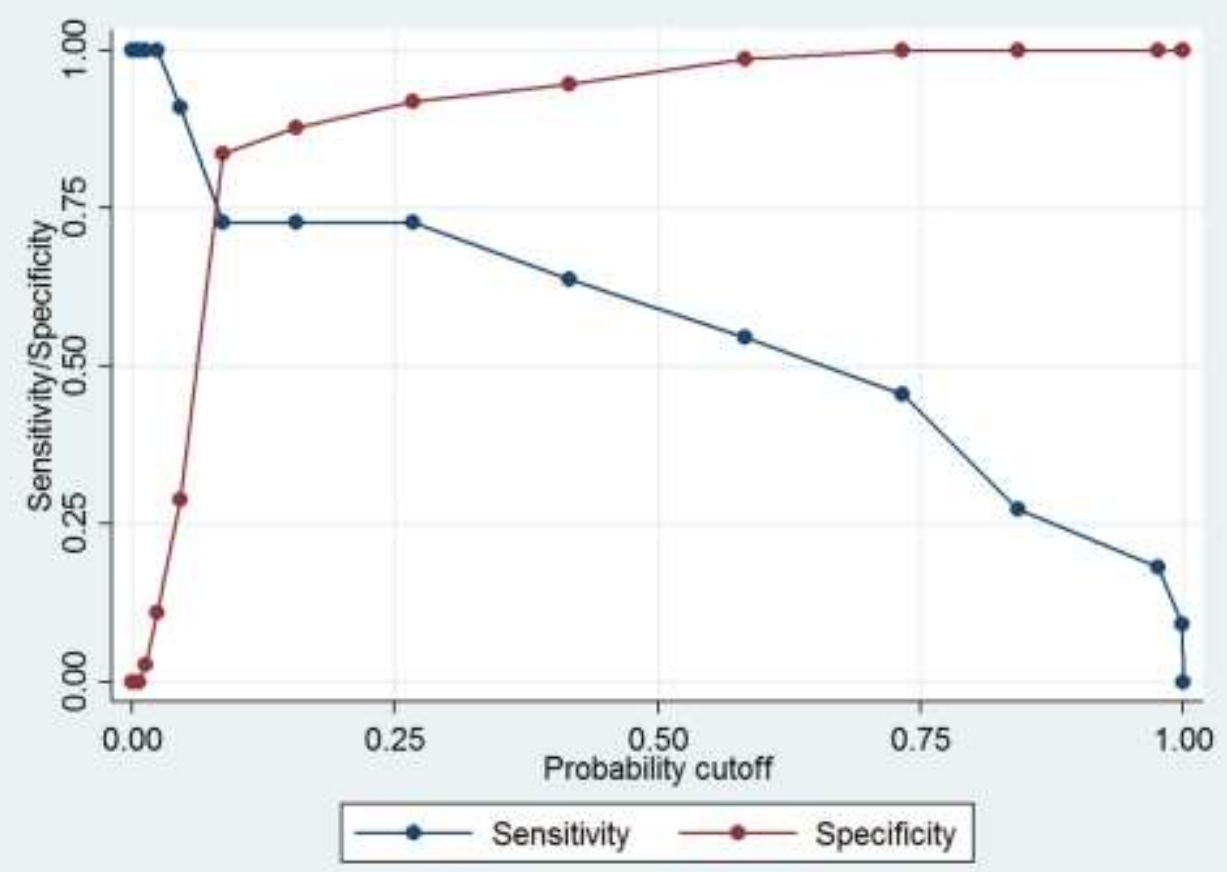

Figure 3: Probability cut-off point of timing of tracheostomy of patients in this study based on sensitivity and specificity.

Predictors of 0- to 23-year mortality were identified by univariate cox proportional hazards analysis initially performed on candidate variables (including the timing of tracheostomy as a potential explanatory variable). Stepwise multivariable Cox regression analysis was performed on the clinically important variables and the independent variables having the probability of $<0.15$ in univariate analysis.
Mortality rates were calculated depending on the total number of years of follow-up for each patient. The survival probability with $95 \%$ confidence intervals was reported at various time intervals with the Kaplan-Meier technique (Figure 4).

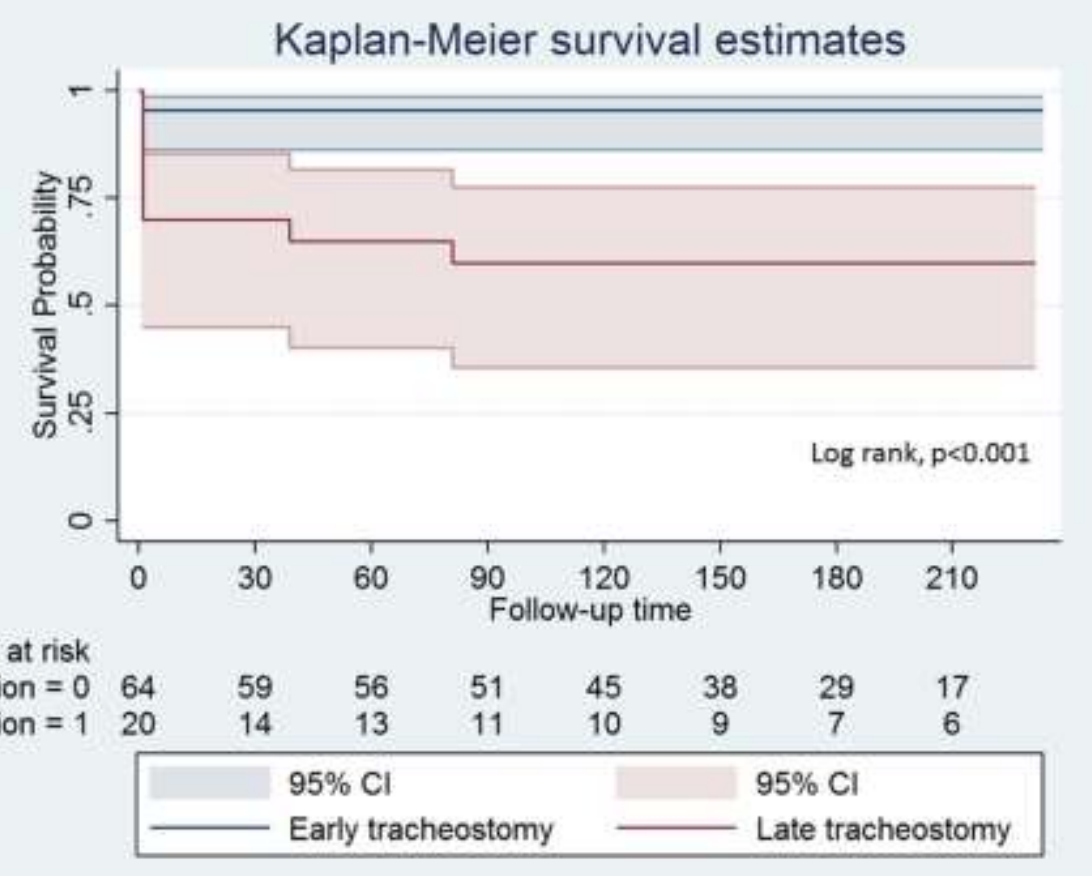




\section{heart surgeries requiring prolonged mechanical ventilation who required tracheostomy $(\log$ rank $p<0.001)$.}

\section{Results}

\section{Study population}

The median age of patients at operation was 4 months (IQR: 23 days-9 months). Twenty-five (29.8\%) patients were younger than 1 month, and $59(70.2 \%)$ were between 1 and 12 months. Thirty (35.7\%) infants in this study population were premature and thirty-nine $(46.4 \%)$ weighed less than $50^{\text {th }}$ percentile of predicted weight by national standards. [21] Twenty-nine (34.5\%) patients required preoperative ventilator support. A combination of three or more risk factors for requiring prolonged mechanical ventilation was present in $58.3 \%(n=49)$ of patients (Tables $1-4)$.

\begin{tabular}{|c|c|c|c|}
\hline Variables & No. of patients & $\begin{array}{c}\text { Hazard ratio (95\% } \\
\text { Confidence Interval) }\end{array}$ & p value \\
\hline $\begin{array}{rr}\text { Age } & \\
-\quad & <1 \text { month } \\
-\quad>1 \text { month } \\
\end{array}$ & $\begin{array}{l}25 \\
59 \\
\end{array}$ & $8.78(2.09-36.84)$ & 0.003 \\
\hline $\begin{array}{c}\text { Prematurity (<37 weeks) } \\
-\quad \text { Yes } \\
-\quad \text { No } \\
\end{array}$ & $\begin{array}{l}30 \\
54 \\
\end{array}$ & $11.14(2.22-55.95)$ & 0.003 \\
\hline $\begin{array}{c}\text { Low birth weight }(<2.5 \mathrm{~kg}) \\
-\quad \text { Yes } \\
-\quad \text { No } \\
\end{array}$ & $\begin{array}{l}39 \\
65 \\
\end{array}$ & $6.45(1.30-31.99)$ & 0.02 \\
\hline $\begin{array}{c}\text { Preoperative ventilation } \\
-\quad \text { Yes } \\
-\quad \text { No } \\
\end{array}$ & $\begin{array}{l}29 \\
55 \\
\end{array}$ & $6.60(1.59-27.32)$ & 0.009 \\
\hline $\begin{array}{c}\text { Genetic syndromes } \\
-\quad \text { Yes } \\
-\quad \text { No } \\
\end{array}$ & $\begin{array}{l}10 \\
74 \\
\end{array}$ & $3.53(0.75-16.47)$ & 0.1 \\
\hline $\begin{array}{c}\text { Preoperative lung infection/lobar collapse } \\
-\quad \text { Yes } \\
-\quad \text { No } \\
\end{array}$ & $\begin{array}{l}19 \\
65\end{array}$ & $2.20(0.57-8.55)$ & 0.25 \\
\hline $\begin{array}{c}\text { Upper airway problems } \\
-\quad \text { Yes } \\
-\quad \text { No } \\
\end{array}$ & $\begin{array}{l}16 \\
68 \\
\end{array}$ & $1.73(0.40-7.42)$ & 0.46 \\
\hline 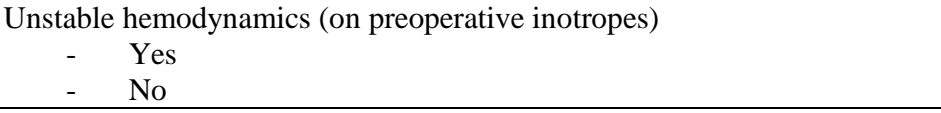 & $\begin{array}{l}39 \\
65 \\
\end{array}$ & $2.24(0.60-8.33)$ & 0.22 \\
\hline $\begin{array}{c}\text { Non-cardiac comorbidities } \\
-\quad \text { Yes } \\
-\quad \text { No } \\
\end{array}$ & $\begin{array}{c}6 \\
78 \\
\end{array}$ & $1.36(0.14-12.86)$ & 0.78 \\
\hline $\begin{array}{c}\text { Preoperative central neurological event } \\
-\quad \text { Yes } \\
-\quad \text { No }\end{array}$ & $\begin{array}{c}5 \\
79 \\
\end{array}$ & $5.18(0.76-35.33)$ & 0.09 \\
\hline $\begin{array}{c}\text { Preoperative sepsis } \\
-\quad \text { Yes } \\
-\quad \text { No }\end{array}$ & $\begin{array}{l}19 \\
65\end{array}$ & $3.51(0.93-13.17)$ & 0.06 \\
\hline $\begin{array}{ll}\text { Surgery } & \text { Before 2011 } \\
& \text { After } 2011 \\
\end{array}$ & $\begin{array}{l}40 \\
44 \\
\end{array}$ & $1.42(0.38,18)$ & 0.49 \\
\hline $\begin{array}{c}\text { Types of surgical procedures } \\
\text { - } \quad \text { Univentricular type of repairs including pulmonary artery } \\
\text { banding, systemic-pulmonary artery shunt } \\
\text { - } \\
\text { Biventricular repair including systemic-pulmonary artery shunt, } \\
\text { pulmonary artery banding, coarctation of aorta }\end{array}$ & 65 & $1.58(0.32-7.99)$ & 0.57 \\
\hline $\begin{array}{c}\text { Cardiopulmonary bypass time } \\
-\quad>120 \text { minutes } \\
-\quad<120 \text { minutes }\end{array}$ & $\begin{array}{l}35 \\
49\end{array}$ & $1.82(0.50-6.52)$ & 0.36 \\
\hline $\begin{array}{c}\text { Aortic cross-clamp time (minutes) } \\
-\quad>60 \text { minutes } \\
-\quad<60 \text { minutes }\end{array}$ & $\begin{array}{l}27 \\
57\end{array}$ & $2.97(0.82-10.79)$ & 0.09 \\
\hline $\begin{array}{l}\text { Unstable hemodynamics on inotropes (postoperative) } \\
-\quad \text { Yes } \\
-\quad \text { No }\end{array}$ & $\begin{array}{l}39 \\
45\end{array}$ & $1.45(0.41-5.19)$ & 0.56 \\
\hline $\begin{array}{l}\text { Timing of tracheostomy after surgery } \\
-\quad 15-30 \text { days }\end{array}$ & 20 & $13.55(3.13-58.61)$ & $<0.001$ \\
\hline
\end{tabular}




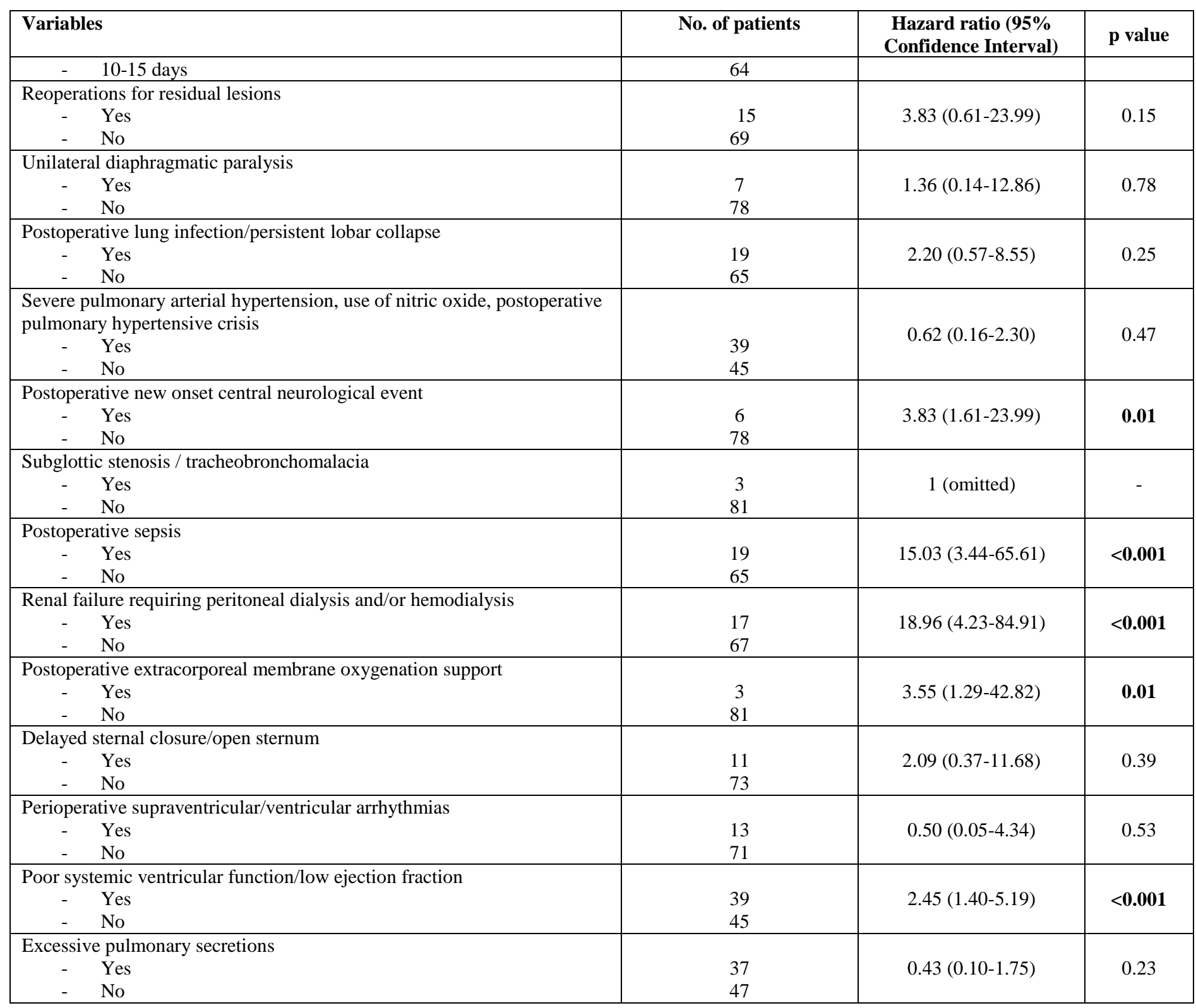

Table 4: Univariate predictors of 0-to 23-year mortality by Cox proportional hazard regression analysis after tracheostomy in infants following surgery for congenital heart disease in this study $(n=84)$

\begin{tabular}{|c|c|c|c|}
\hline Patient related variables & $\begin{array}{c}\text { Early tracheostomy } \\
(n=64)\end{array}$ & $\begin{array}{l}\text { Late tracheostomy } \\
(n=20)\end{array}$ & P value \\
\hline Age ( $\leq 1$ months $)$ & $18(4.7 \%)$ & $7(35 \%)$ & 0.37 \\
\hline Prematurity & $19(28.1 \%)$ & $11(55 \%)$ & $\mathbf{0 . 0 3}$ \\
\hline Low birth weight & $27(42.2 \%)$ & $12(60 \%)$ & 0.2 \\
\hline Preoperative ventilation & $18(28.1 \%)$ & $11(55 \%)$ & 0.02 \\
\hline Genetic syndrome (yes) & $8(12.5 \%)$ & $2(10 \%)$ & 0.76 \\
\hline Preoperative lung infection/lobar collapse & $15(23.4 \%)$ & $4(20 \%)$ & 1.0 \\
\hline Upper airway problem & $12(18.7 \%)$ & $4(20 \%)$ & 1.0 \\
\hline Non-cardiac comorbidities & $6(9.4 \%)$ & $0(0 \%)$ & 0.15 \\
\hline
\end{tabular}




\begin{tabular}{|c|c|c|c|}
\hline Preoperative central neurological event & $3(4.7 \%)$ & $2(10 \%)$ & 0.38 \\
\hline Preoperative sepsis & $14(21.8 \%)$ & $5(25 \%)$ & 0.76 \\
\hline Indications for tracheostomy & $25(39.1 \%)$ & $20(100 \%)$ & $<0.001$ \\
\hline Reoperation & $1(1.6 \%)$ & $5(25 \%)$ & 0.003 \\
\hline Unilateral diaphragmatic paralysis & $1(1.6 \%)$ & $5(25 \%)$ & 0.003 \\
\hline Preoperative lung infection & $9(14.1 \%)$ & $10(50 \%)$ & 0.001 \\
\hline Presence of pulmonary arterial hypertension & $33(51.5 \%)$ & $6(30 \%)$ & 0.12 \\
\hline Cerebral hemorrhage & $2(3.1 \%)$ & $4(20 \%)$ & 0.02 \\
\hline Tracheobronchomalacia & $1(1.6 \%)$ & $2(10 \%)$ & 0.14 \\
\hline Renal dysfunction requiring peritoneal/hemodialysis & $6(9.4 \%)$ & $11(55 \%)$ & $<0.001$ \\
\hline Postoperative extracorporeal membrane oxygenation support & 0 & $3(15 \%)$ & 0.012 \\
\hline Delayed sternal closure / open sternum & $3(4.7 \%)$ & $8(40 \%)$ & 0.002 \\
\hline Perioperative supraventricular/ ventricular arrhythmias & $9(14.1 \%)$ & $4(20 \%)$ & 0.49 \\
\hline Poor systemic ventricular function/ low ejection fraction & $26(40.1 \%)$ & $13(65 \%)$ & 0.07 \\
\hline Excessive pulmonary secretions & $26(40.1 \%)$ & $11(55 \%)$ & 0.30 \\
\hline Unstable hemodynamics on preoperative inotropes & $28(43.7 \%)$ & $11(55 \%)$ & 0.37 \\
\hline Postoperative unstable hemodynamics & $21(32.8 \%)$ & $18(90 \%)$ & $<0.001$ \\
\hline Aortic cross-clamp time $>60$ minutes & $9(14.1 \%)$ & $18(90 \%)$ & $<0.001$ \\
\hline Cardiopulmonary bypass time $>120$ minutes & $25(39.1 \%)$ & $10(50 \%)$ & 0.38 \\
\hline Mortality & $3(4.7 \%)$ & $8(40 \%)$ & $<0.001$ \\
\hline
\end{tabular}

\section{ICU-Intensive care unit}

Table 5: Preoperative and intraoperative variables examined in each surgical group

A total of $10(11.9 \%)$ patients had a genetic syndrome. Common genetic syndromes included trisomy $21(\mathrm{n}=3)$, DiGeoerge syndrome $(\mathrm{n}=2)$, congenital rubella syndrome $(\mathrm{n}=2)$, Pierre Robin syndrome (Glossoptosis, $\mathrm{n}=1$ ), and VACTERL (vertebral abnormalities, anal atresia, cardiac abnormalities, tracheoesophageal fistula and/or esophageal atresia, renal agenesis and dysplasia, and limb defects, $n=2$ ). These patients had significant neurodevelopmental impairment in combination with chromosomal abnormalities. The underlying cardiac diagnoses for patients requiring tracheostomy are shown in Table 1 and 2. (Definitions). In this study, $64(76.2 \%)$ patients underwent tracheostomy between $10^{\text {th }}$ $15^{\text {th }}$ postoperative day and $20(23.8 \%)$ patients underwent tracheostomy between 15-30 days following "primary operation" (Video Presentation).

\begin{tabular}{|l|c|c|c|}
\hline Variables & Early tracheostomy & Late tracheostomy & P value \\
\hline Discharge mortality & $2(2.4 \%)$ & $7(8.3 \%)$ & $<\mathbf{0 . 0 0 1}$ \\
\hline ICU length of stay (days) & $18 \pm 12$ & $42 \pm 25$ & $<\mathbf{0 . 0 0 1}$ \\
Mean \pm SD, median (range) & $12(8-22)$ & $(3728-74)$ & \\
\hline $\begin{array}{l}\text { Duration of mechanical ventilation from the time } \\
\text { of primary operation (days) }\end{array}$ & $13 \pm 11$ & $31 \pm 15$ & $<\mathbf{0 . 0 0 1}$ \\
Mean \pm SD, median (range) & $9(7-15)$ & $25(17-58)$ & \\
\hline Time of decanulation (days) & $14 \pm 9$ & $29 \pm 14$ & $<\mathbf{0 . 0 0 1}$ \\
\hline Postoperative sepsis & $11(8-19)$ & $20(17-34)$ & \\
\hline Lower respiratory tract infection / lobar collapse & $6(7.1 \%)$ & $13(15.4 \%)$ & $<\mathbf{0 . 0 0 1}$ \\
\hline Cardiac morbidity & $7(8.3 \%)$ & $12(14.3 \%)$ & $<\mathbf{0 . 0 0 1}$ \\
\hline Subglottic stenosis / tracheobronchomalacia & $10(11.9 \%)$ & $19(22.6 \%)$ & $<\mathbf{0 . 0 0 1}$ \\
\hline
\end{tabular}

In order to understand/analyze the outcome difference between early and late tracheostomy, the preoperative (pre-tracheostomy) status difference between two groups were analyzed. Descriptive characteristics and underlying cardiac diagnoses are summarized in table 1 . The groups did not differ significantly in regard to age, sex, low birth weight, genetic syndrome, upper airway problems, preoperative lung infection/lobar collapse, sepsis, central neurological event, presence of excessive pulmonary secretions, poor systemic ventricular function, and unstable hemodynamics on preoperative inotropes (Table 5). 
Table 6: Mortality and morbidity between early and late tracheostomy in patients undergoing surgery for congenital heart diseases in the study $(n=84)$

There were significant differences between groups in regard to prematurity $(\mathrm{p}=0.03)$, preoperative ventilation $(\mathrm{p}=0.02)$, preoperative lung infection $(\mathrm{p}=0.001)$, renal dysfunction requiring peritoneal/hemodialysis $(\mathrm{p}<0.001)$, requirement of postoperative extracorporeal membrane oxygenation $(\mathrm{p}=0.012)$, delayed sternal closure/open sternum ( $\mathrm{p}=0.002)$, cerebral hemorrhage $(\mathrm{p}=0.02)$, unilateral diaphragmatic paralysis requiring diaphragmatic plication $(\mathrm{p}=0.003)$, postoperative unstable hemodynamics $(\mathrm{p}<0.001)$, prolonged aortic crossclamp time $(\mathrm{p}=<0.001)$, and requirement of reoperation $(\mathrm{p}=0.003)$ (Table $5)$.

\section{Short-term outcomes}

There were $9(10.8 \%)$ perioperative deaths after tracheostomy while still ventilated through the tracheostomy within 30 days following surgery. A combination of three or more risk factors was responsible for death in all patients. In 7 neonates, the causes of mortality were prematurity with low birth weight requiring preoperative ventilator support, lung collapse and sepsis who developed renal failure requiring peritoneal dialysis/hemodialysis and ultimately died of multiorgan dysfunction. One patient died of diffusely hypoxic cerebral injury and another patient died of new onset postoperative intracranial haemorrhage and cerebral coning.

Discharge mortality $(2.4 \%$ vs $8.3 \%, \mathrm{p}<0.001)$ and cardiac morbidity $(11.9 \%$ vs $22.6 \%, p<0.001)$ was lower in the early tracheostomy group.
Early tracheostomy was associated with decreased duration of mechanical ventilation $(13 \pm 11$ vs $31 \pm 15$ days, $\mathrm{p}<0.001)$, ICU length of stay $(18 \pm 12$ vs $42 \pm 25$ days, $p<0.001)$ and decreased time of decannulation $(14 \pm 9$ vs $29 \pm 14, p<0.001)$ days. The overall postoperative sepsis was lower in the early tracheostomy group $(7.1 \%$ vs $15.4 \%, \mathrm{p}<0.001)$. There were no cases of mediastinitis in either group (Table 6)

Neonates, prematurity ( $<37$ weeks), low birth weight $(<2.5 \mathrm{~kg})$, preoperative ventilation, tracheostomy performed beyond 15 days of cardiac surgery, postoperative new onset cerebral hemorrhage, hypoxic cerebral injury, renal failure requiring peritoneal dialysis/hemodialysis, neonates requiring ECMO, LVEF $(<0.40)$ and postoperative sepsis were significant negative factors for survival according to univariate analysis (Table 4).

Multivariate analysis identified six predictors for death after tracheostomy in this study group. The risk of death was 5.26 times higher (95\% CI: 1.47, 20.36) in infants undergoing late tracheostomy (beyond 15 days) as compared to early tracheostomy ( $\mathrm{p}=0.001$ ). Neonates with renal failure requiring peritoneal dialysis/hemodialysis also exhibited 19.37 times (2.22-168.37) higher risk of death following surgery $(\mathrm{p}=0.007)($ Table 7$)$.

\begin{tabular}{|l|c|c|}
\hline Variables (covariates adjusted) & $\begin{array}{c}\text { Hazard ratio (95\% } \\
\text { confidence interval) }\end{array}$ & p value \\
\hline Age (<1 month)* & $6.09(1.54,24.02)$ & $\mathbf{0 . 0 1}$ \\
\hline Preoperative requirement of ventilation* & $5.21(1.35,20.15)$ & $\mathbf{0 . 0 1}$ \\
\hline Renal failure requiring peritoneal dialysis and/or hemodialysis* & $19.37(2.22,168.37)$ & $\mathbf{0 . 0 0 7}$ \\
\hline Timing of tracheostomy after surgery (>15 days)* & $5.26(1.47,20.36)$ & $\mathbf{0 . 0 0 1}$ \\
\hline Postoperative sepsis* & $6.72(1.74,25.93)$ & $\mathbf{0 . 0 0 6}$ \\
\hline $\begin{array}{l}\text { Postoperative new onset central neurological event } \\
\text { (hemorrhage/hypoxic/embolism)* }\end{array}$ & $18.59(1.61,214.44)$ & $\mathbf{0 . 0 1}$ \\
\hline
\end{tabular}

*Variables with increased risk

Table 7: Predictors of 0- to 23-year mortality by Cox proportional hazard regression analysis applied to all 84 patients

\section{Long-term outcomes}

There were $2(2.7 \%)$ late deaths 39 and 81 months after surgery due to renal failure $(n=1)$ and cerebral thrombosis $(n=1)$ respectively. One patient was lost to follow-up. Seventy-two patients $(98.6 \%)$ were followed up for a period of 1-276 month and yielded 885.6 patient-years of data. At a median follow-up of 166 (IQR: 82.5-116) months, the actuarial survival was $86.61 \%$ (SE $\pm 0.04 \%$; 95\% CI: 77.1, 92.3). The actuarial survival was significantly lower in patients undergoing late tracheostomy (log rank p<0.0001), (Figure 4).

\section{Cohort of survivors}

At the completion of the period of review, 73 children were known to be alive. Late follow-up data was not available for one patient. All survivors $(n=72)$ were examined and studied between June 2019 and December 2019, which was the closing interval of the study. Postoperative evaluation consisted of six monthly clinical examination, electrocardiogram, chest radiograph, soft tissue x-ray of the neck and echocardiogram. The severity of congestive heart failure was assessed according to Ross clinical score. [22]

Preoperative respiratory insufficiency was present in $55(65.5 \%)$ of 84 infants, of whom $29(34.5 \%)$ were already intubated and ventilated, and the remainder were not intubated but were oxygen dependent. The median total duration of mechanical ventilation before tracheostomy was 20 days (10-28 days). The interval between the primary operation and tracheostomy was 10 days in $23(27.3 \%)$ infants, 15 days in $41(48.8 \%)$ infants, and 30 days in 20 (23.8\%) infants (Table 2).

Ventilation could not be weaned sufficiently to allow a trial of extubation in $39(46.4 \%)$ patients. In $38(45.2 \%)$ cases extubation had failed on single occasion and in $7(8.3 \%)$ cases on two occasions. The reasons for prolonged ventilation were multifactorial for most patients. Cardiac cachexia, malnutrition, persistent postoperative pulmonary arterial hypertension, extremely poor body muscle reserves were other factors for requirement of prolonged ventilation in $39(46.4 \%)$ infants (Table 3 ).

Neurological comorbidity was present in a total of 21 (25\%) infants: six had experienced new insults, and five had pre-existing stroke, and 10 $(11.9 \%)$ had major neurodevelopmental abnormalities. One infant had unilateral vocal cord palsy. Persistent chylothorax requiring prolonged intercostal drainage and reoperation affected four infants (Table 3).

Of the 84 children, $15(17.8 \%)$ required cardiothoracic reoperations due to various causes. Two (2.4\%) patients required revision of transannular patch. Two $(2.4 \%)$ patients underwent tracheal operations for tracheal stenosis, $4(4.7 \%)$ patients required ligation of the thoracic duct for 
chylothorax, and $7(8.3 \%)$ patients required unilateral diaphragmatic plication (before tracheostomy).

Decannulation was successful in all 72 infants. The median duration of mechanical ventilation after tracheostomy was 22 days (range 11-35 days) and the median total duration of ventilator support (before and after tracheostomy) was 37 days (20-48 days). The median duration of tracheostomy to decannulation in survivors was 31 days (30-52 days). Sixty-eight $(94.4 \%)$ survivors were in Ross's clinical score of 2 and without antifailure cardiac medications. [22] There were no reoperations during this period.

\section{Complications of tracheostomy}

One infant with tracheobronchomalacia had local infection at the tracheostomy site and the tracheostomy was exchanged for a period of nasotracheal ventilation. After the infection had cleared, the tracheostomy wound was revised without any further complications. Two children with subglottic stenosis who were preoperatively ventilated for 15 and 20 days respectively underwent excision of subglottic membrane and cricoid splinting and were ventilated for a period of 3 weeks in two sessions. There were no other complications, directly related to tracheostomy.

\section{Prolonged tracheostomy ventilation}

Preoperative ventilation before the "primary operation", preoperative respiratory insufficiency, subglottic stenosis, tracheobronchomalacia, diaphragmatic paralysis, cardiac cachexia, and sepsis were associated with a longer period of tracheostomy ventilation. At the end of the followup, all survivors were successfully decannulated.

\section{Analysis of the ROC curve, sensitivity and specificity plot}

Tracheostomy performed between $12^{\text {th }}$ and $14^{\text {th }}$ postoperative day was associated with $100 \%$ sensitivity and $10.9 \%$ specificity in terms of superior clinical outcome. The timing of tracheostomy of 15 days as the optimal cut-off point was associated with a sensitivity of $73 \%$ and specificity of $84 \%$, and at this time point, the Youden's index was 0.60 . The results obtained from the area under the ROC curve indicate that $83 \%$ (SE $\pm 0.083,95 \%$ CI $67.4,1.0$ ) of the time, the clinical outcome of postoperative patients was superior when tracheostomy was performed between $12^{\text {th }}$ and $15^{\text {th }}$ postoperative days compared with those performed between $15^{\text {th }}$ and $30^{\text {th }}$ postoperative days. Analysis of the sensitivity and specificity plot revealed the timing of the tracheostomy with an optimal cut-off point $<16$ days, Youden's value of 0.64 and was associated with a sensitivity of $73 \%$ and specificity of $91 \%$ (Figures 2, 3).

\section{Discussion}

\section{Indications}

The need for prolonged mechanical ventilation was a result of multifactorial etiology in over half of our patient cohort $(49,58.3 \%)$, most common being suboptimal hemodynamics due to cardiac cause in conjunction with renal failure requiring peritoneal dialysis and sepsis. On individual basis, the leading causative factors were cardiac cachexia (46.4\%), severe cardiac-related pulmonary arterial hypertension (46.4\%), followed by unstable hemodynamics $(41.6 \%)$, persistent pulmonary infection, lung collapse \& sepsis $(22.6 \%)$, renal failure requiring peritoneal dialysis/hemodialysis (20.2\%), and craniofacial syndromes with upper airway problems (19\%) (Table 2). A number of studies found no association between surgical complexity and cardiac diagnoses with extubation failure. [1-11,18,19] However, other studies reported a history of pulmonary hypertension, prolonged CPB duration, deep hypothermic circulatory arrest, chromosomal abnormalities, and a high dose of narcotics as risk factors for extubation failure. [1-11,18,19]
Tracheobronchomalacia has been reported in $4 \%$ to $12 \%$ of young infants with CHD. [23-25] Additionally, it is not uncommon for patients with CHD to have a dysmorphic upper airway and genetic disorders. In this study, one infant had tracheobronchomalacia and two infants had subglottic stenosis requiring excision of the subglottic membrane. Although our patient cohort was not specifically evaluated for ciliary dysfunctional status, it remains an important consideration in syndromic patients. [26] Although not demonstrated in our study group, children with CHD might be at high-risk for airway compression by virtue of the anatomic proximity of cardiac chambers and great vessels to the central airways. [1-10]

Diaphragmatic paresis/ paralysis is less well tolerated in infants and small children due to relative weakness of the intercostal muscles, greater compliance of the chest wall, horizontal orientation of the rib cage, and increased mediastinal mobility with shifting of the mediastinal contents to the contralateral side on inspiration. Additionally, the recumbent position of infants reduces the vital capacity and small calibre of the infant bronchial tree, facilitates retention of secretions and bronchial obstructive debris. [27,28] Unilateral diaphragmatic paralysis reduces pulmonary function by about $25 \%$ in older children and by up to $60 \%$ in infants. $[27,28]$

The causative factors include intraoperative use of iced saline, cauteryinduced neuropraxia, neurotemesis, surgical dissection close to the phrenic nerve, and staged palliation for univentricular repairs. The reported prevalence in retrospective studies varies from $0.3 \%$ to $5.7 \%$. $[27,28]$ In prospective studies, the reported incidence varies from $1.9 \%$ to $23.8 \%$, which may indicate increased surveillance in prospective studies to detect asymptomatic cases. [27,28] In our cohort, 7 (8.3\%) patients underwent plication for unilateral diaphragmatic paresis, however, it was not a significant factor in mortality. The opinion on timing of diaphragmatic plication varies from immediate plication on diagnosis, to a waiting period of 1-6 weeks in anticipation of spontaneous recovery. [27,28] In general, an arbitrary figure of 2-3 weeks of symptomatic diaphragmatic paralysis is advocated for diaphragmatic plication. [27,28]

\section{Outcomes}

Children requiring tracheostomy after surgery for CHD are at significant risk of poor outcomes with less than half still alive at a median follow-up of 3.9 years. [2-11] Mastropietro analysed 606 tracheostomies in neonates and infants in the STS Congenital Heart Surgery database in 2016 and found an overall mortality rate of $25.2 \%$. [6] Johnson and associates in a multi-institutional study on 1292 tracheostomies in children undergoing cardiac surgeries reported an overall mortality rate of $21.6 \%$ (range $0 \%$ to $50 \%)$. [1]

Our overall mortality of $10.7 \%$ are in accordance with the published investigations which documents a tracheostomy-related mortality rate between $3.2 \%$ and $25 \%$ after 1985. [1-11] If a patient could not be extubated, we tried to identify anatomic or physiologic causes that were potentially reversible, e.g. plication of a paralysed diaphragm, optimization of hemodynamics with inotropic support, and nutritional supplementation to alleviate chronic cardiac cachexia. The decision of tracheostomy was taken before attempting second extubation in $45.2 \%$ $(n=38)$ of infants, and following failed second extubation in $8.3 \%(n=7)$ of infants. Ventilation could not be weaned sufficiently to allow a trial of extubation in $39(46.4 \%)$ infants.

In our study, logistic regression analysis accounting for the effects of other factors demonstrated neonatal intervention, ventilation requirement in the preoperative period because of unstable hemodynamics, renal failure requiring peritoneal/ hemodialysis, postoperative sepsis, postoperative new-onset cerebral hemorrhage, hypoxic cerebral injury as significant negative factors for survival. The risk of death was 5.26 times 
higher (95\% CI: 1.47, 20.36) in infants undergoing tracheostomy beyond 15 days following surgery in comparison to those undergoing tracheostomy between 10 and 15 days following surgery (Table 7). All of our patients underwent open surgical procedure for tracheostomy. In this study, a midline vertical incision through the $2^{\text {nd }}$ to $4^{\text {th }}$ tracheal cartilages was used in all cases, thus minimizing incision of tracheal rings as few as possible.

Stomaplasty techniques described by Eliacher, Koltai and Bjork involves resection of tracheal cartilages and are recommended when longer duration of tracheostomy is expected.[17,29,30] We did not use any of these methods, since we expected our patients to be decannulated before discharge from hospital.

The reported incidence of tracheostomy-related complication is around $15 \%$ in adults and $15-19 \%$ in children. [1-11] Tracheitis was the most common complication in the reported literature followed by tracheostomy site breakdown. Other complications include tracheo-brachiocephalic artery fistulization, and mediastinitis. [31-35] Except for one infant who developed local infection at the site of tracheostomy, which was managed conservatively, and two children with subglottic stenosis, no other patients developed tracheostomy-related complications. We have a dedicated multidisciplinary team comprising of intensivists, tracheostomy nurses, chest physicians, ENT surgeons who carry out regular reassessments of all these patients while inpatient and after discharge. In our study population, we have been able to decannulate all infants prior to discharge. Due to lack of health care resources, hospital discharge with a tracheostomy or ventilator is not a viable option in India, therefore in-hospital decannulation is preferable in our setup.

We were particularly encouraged to find that there were no cases of mediastinitis in our group. Published reports on the incidence of mediastinitis following tracheostomy are varied from nil to significant risk by different investigators. [1-11,31-35] Some authors have demonstrated an increased risk of mediastinitis with tracheostomy following sternotomy in adult patients. [31,34] Percutaneous tracheostomy has been incriminated as a risk factor for mediastinitis by some investigators. [31,34,35] Two (2.4\%) patients in this study developed spontaneous pneumothorax immediately following decannulation of the tracheostomy tube requiring intercostal drainage.

Five $(6.8 \%)$ patients had superficial wound infection, which was managed conservatively. In case of clinical (fever, superficial wound infection, chest findings), laboratory (leukocytosis, elevated C-reative protein, procalcitonin), or radiological evidence (pneumonia), we begin broad spectrum antibiotics, and switch over to culture directed therapy on an individualized basis later on. The antibiotics were stopped when these features resolved.

Following placement of the tracheostomy tube, one of the concerns is the duration of time that the patient remains dependent on the device. In our study, all our patients were successfully weaned from positive pressure ventilation at a variable time period. Patients undergoing early tracheostomy were decannulated earlier than those undergoing late tracheostomy (mean, $14 \pm 9$ vs $29 \pm 14$ days; $\mathrm{p}<0.001$ ).

\section{Comparing outcomes in early and late tracheostomy}

There is no consensus in the published literature on the indications and the duration a child should remain endotracheally intubated prior to tracheostomy and on the optimal pediatric decannulation protocol. [1-10]

Tracheostomy performed between $12^{\text {th }}$ and $14^{\text {th }}$ postoperative day was associated with $100 \%$ sensitivity and $10.9 \%$ specificity in terms of superior clinical outcome using the timing of tracheostomy of 15 days as the optimal cut-off point was associated with a sensitivity of $73 \%$ and specificity of $84 \%$, and at this time point, the Youden's index was 0.60 .
The results obtained from the area analysis of ROC curve indicate that $83 \%$ of standard error (SE) $\pm 0.083,95 \%$ CI $67.4,1.0$ ) of the time, the clinical outcome postoperative patients was superior when tracheostomy was performed between $12^{\text {th }}$ and $15^{\text {th }}$ postoperative days compared with those performed between $15^{\text {th }}$ and $30^{\text {th }}$ postoperative days.

In this study, $22.6 \%(\mathrm{n}=19)$ had postoperative sepsis and was associated with 6.72 times $(1.74,25.92)$ increased risk of death on logistic regression analysis (Table 7). We believe that early tracheostomy leads to a decreased need for sedation, allows a gradual increase in the volume of enteral/parenteral feeds, thus improving nutrition, allows gradual weaning of ventilatory support, improves hemodynamics, shortens ICU stay and improves pulmonary toilet. [1-11]

In our cohort, ICU mortality and cardiac morbidity was significantly lower in the early tracheostomy group. Early tracheostomy was associated with decreased duration of mechanical ventilation, length of ICU stay, and decreased time of decannulation days. The overall postoperative sepsis was lower in the early tracheostomy group. There were no cases of mediastinitis in either group. However, adverse outcomes like sepsis, low cardiac output syndrome/suboptimal hemodynamics, delayed sternal closure, cardiothoracic reoperations were responsible for delaying tracheostomy placement, and thus more likely the plausible reasons for the differences seen in mortality.

\section{Study Limitations}

This study has several limitations. The study spans 23 years over which almost all aspects of intensive care have changed. Given its retrospective design, there may have been unmeasured confounding factors that influenced the observed outcomes and a prospective randomized trial of tracheostomy timing would be challenging given the small number of pediatric cardiac surgical patients who require prolonged ventilation, the diversity of diagnoses, and associated congenital and developmental factors. Short of randomization, propensity matching is probably the best protection against confounding and selection bias. Despite this, there may be confounding factors even propensity matching cannot overcome.

As this was a single surgeon study, it may not be possible to directly extrapolate the reported findings to other clinical settings. For example, the ventilation weaning protocols and extubation readiness test can vary among ICUs. Center-to-center variations in indications for tracheostomy, the timing of tracheostomy, and post tracheostomy care could potentially influence the outcomes. The small number of patients in this study, and the large number of candidate predictors analyzed in this study also limit the validity of results.

The study institution likely has a referral bias for high-risk patients with complex CHD, prematurity, late presentation, a referral from outside the geographic area. Additionally, a large proportion of the group having biventricular or univentricular repair had genetic syndromes or significant noncardiac comorbidities, which may reflect referral bias as well. Despite the limitations as above, the prevalence of extubation failure and the airway diseases in this study were comparable with recently published studies including high-risk cardiac surgical patients. However, our outcomes and possible risk factors need to be confirmed by larger multicenter studies with further investigation.

\section{Conclusions}

Our study demonstrates the relatively high incidence and diverse etiologies of extubation failure in pediatric cardiac surgery. We conclude that tracheostomy in neonates and infants undergoing cardiac surgeries, requiring prolonged mechanical ventilation provide a stable airway with improved pulmonary toilet, secures airway control, allows patient mobilization, allows the adequate intake of nutrients, thus improving 
cardiac cachexia and body mass, reduces work of breathing and allows gradual weaning from ventilation.

The timing of tracheostomy placement as it relates to the overall duration of positive pressure ventilation and survival between 10-15 days after surgery with the partially healed wound and mediastinal tissues appears safe. Early tracheostomy within $15^{\text {th }}$ postoperative day was associated with decreased ICU mortality, decreased morbidity, and decreased ICU stay compared with tracheostomy between 15 and 30 days.

\section{Conflict of interest: No potential conflicts exist}

\section{Source of funding: Nil}

\section{Informed consent and Patient identification release}

Statement: Obtained from all patients

\section{References}

1. Johnson JT, Marino BS, Klugman D, Shamszad P. Natioanl variation in the use of tracheostomy in patients with congenital heart disease. Pediatr Crit Care Med 2017; 18(10): 958-964

2. Cotts T, Hirsch J, Thorne M, Gajarski R. Tracheostomy after pediatric cardiac surgery: frequency, indications, and outcomes. J Thorac Cardiovasc Surg. 2011;141 (2): 413-418.

3. Hoskote A, Cohen G, Goldman A, Shekerdemian L. Tracheostomy in infants and children after cardiothoracic surgery: indications, associated risk factors, and timing. J Thorac Cardiovasc Surg. 2005;130 (4): 1086-1093.

4. Polito A, Patorno E, Costello JM et al. Perioperative factors associated with prolonged mechanical ventilation after complex congenital heart surgery. Pediatr Crit Care Med 2012; 12: e122e126

5. Rosner E, Mastropietro CW. Prior cardiac surgery is independently associated with decreased survival following infant tracheostomy. Respir Care 2015;60: 47-55.

6. Mastropietro $\mathrm{CW}$, Benneyworth $\mathrm{BD}$, Turrentine $\mathrm{M}$ et al. Tracheostomy after operations for congenital heart disease: an analysis of the Society of Thoracic Surgeons congenital heart surgery database. Ann Thorac Surg 2016; 101: 2285-2292

7. LoTempio MM, Shapiro NL. Tracheostomy tube placement in children following cardiothoracic surgery: indications and outcomes. Am J Otolaryngol. 2002; 23: 337-340.

8. Rossi AF, Fishberger S, Hannan RL, et al. Frequency and indications for tracheostomy and gastrostomy after congenital heart surgery. Pediatr Cardiol. 2009;30:225-231.

9. Berry J, Graham R, Roberson D, et al. Patient characteristics associated with in-hospital mortality in children following tracheotomy. Arch Dis Child 2010; 95: 703-710.

10. Yavas S, Yagar S, Mavioglu L, et al. Tracheostomy: how and when should it be done in cardiovascular surgery ICU? J Card Surg 2009; 24: 11-18.

11. Costello JP, Emerson DA, Shu MK, et al. Outcomes of tracheostomy following congenital heart surgery: A contemporary experience. Congenit Heart Dis. 2015; 10: E25-E29

12. Allen TH, Steven IM. Prolonged endotracheal intubation in infants and children. Br J Anaesth. 1998; 81: 473-481.

13. Benjamin B. Prolonged intubation injuries of the larynx: endoscopic diagnosis, classification, and treatment. Ann Otol Rhinol Laryngol Suppl. 1993; 160: 1-15.

14. Hawkins DB. Glottic and subglottic stenosis from endotracheal intubation. Laryngoscope. 1977; 87: 339-346.

15. Nicklaus PJ, Crysdale WS, Conley S, White AK, Sendi K, Forte V. Evaluation of neonatal subglottic stenosis: a 3-year prospective study. Laryngoscope. 1990; 100: 1185-1190.
16. Santos PM, Afrassiabi A, Weymuller EA Jr. Risk factors associated with prolonged intubation and laryngeal injury. Otolaryngol Head Neck Surg. 1994; 111: 453-459.

17. Midwinter KI, Carrie S, Bull PD. Paediatric tracheostomy: Sheffield experience 1979-1999. J Laryngol Otol. 2002; 116: 532535.

18. Combes A, Luyt CE, Nieszkowska A. Is tracheostomy associated with better outcomes for patients requiring long-term mechanical ventilation? Crit Care Med. 2007;35 (3): 802-807.

19. Rodriguez JL, Steinberg SM, Luchetti FA, et al. Early tracheostomy for primary airway management in the surgical critical care setting. Surgery 1990; 108: 655-659.

20. Jacobs JP, Mavroudis C, Jacobs ML, et al. What is operative mortality? Defining death in a surgical registry database: a report of the STS Congenital Database Taskforce and the Joint EACTSSTS Congenital Database Committee. Ann Thorac Surg. 2006;81 (5): 1937-1941.

21. World Health Organization. Global nutrition targets 2025: low birth weight policy brief (WHO/NMH/NHD/14.5). Geneva: World Health Organization, 2014.

22. Ross RD, Bollinger RO, Pinsky WW. Grading the severity of congestive heart failure in infants. Pediatr Cardiol 1992; 13: 7275

23. Gupta P, McDonald R, Gossett JM, et al. A single-center experience of extubation failure in infants undergoing the Norwood operation. Ann Thorac Surg 2012;94: 1262-1268.

24. Bandla HP, Hopkins RL, Beckerman RC, Gozal D. Pulmonary risk factors compromising postoperative recovery after surgical repair for congenital heart disease. Chest. 1999;116: 740-747.

25. Kanter RK, Bove EL, Tobin JR, Zimmerman JJ. Prolonged mechanical ventilation of infants after open heart surgery. Crit Care Med. 1986;14 (3): 211-214.

26. Harden B, Tian X, Giese R, et al. Increased postoperative respiratory complications in heterotaxy congenital heart disease patients with respiratory ciliary dysfunction. J Thorac Cardiovasc Surg. 2014; 147 (4): 1291-1298.

27. Akay TH, Ozkan S, Gultekin B. Diaphragmatic paralysis after cardiac surgery in children: incidence, prognosis, and surgical management. Pediatr Surg Int. 2006; 22: 341-346.

28. Mok Q, Ross-Russell R, Mulvey D, et al. Phrenic nerve injury in infants and children undergoing cardiac surgery. Br Heart $\mathrm{J}$. 1991;65: 287-292.

29. Ruggiero FP, Carr MM. Infant tracheotomy: results of a survey regarding technique. Arch Otolaryngol Head Neck Surg 2008; 134(3): 263-267.

30. Koltai PJ. Starplasty: a new technique of pediatric tracheotomy. Arch Otolaryngol Head Neck Surg 1998; 124(10): 1105-1111.

31. Ryan DW, Kilner AJ. Another death after percutaneous dilational tracheostomy. Br J Anaesth. 2003; 91(6): 925-926.

32. Shlugman D, Satya-Krishna R, Loh L. Acute fatal haemorrhage during percutaneous dilatational tracheostomy. $\mathrm{Br} \mathrm{J}$ Anaesth 2003; 90(4): 517-520.

33. Durbin CG Jr. Early complications of tracheostomy. Respir Care. 2005; 50 (4): 511-515.

34. Curtis JJ, Clark NC, McKenney CA, et al. Tracheostomy: a risk factor for mediastinitis after cardiac operation. Ann Thorac Surg. 2001;72: 731-734.

35. Stamenkovic SA, Morgan IS, Pontefract DR, Campanella C. Is early tracheostomy safe in cardiac patients with median sternotomy incisions? Ann Thorac Surg. 2000; 69(4): 1152-1154.

36. Chowdhury UK, Kothari SS, Patel CD, et al. An alternative technique for transfer of anomalous left coronary artery from the 
pulmonary trunk in children and adults using autogenous aortic and pulmonary arterial flaps. Cardiol Young 2008; 18: 165-176.

\section{Video Presentation}

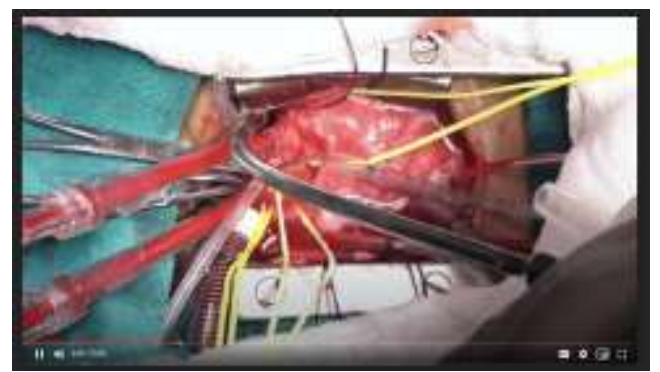

A presentation of an alternative technique for transfer of anomalous origin of left coronary artery from the pulmonary trunk in a child using autogenous aortic and pulmonary arterial flaps who underwent subsequent tracheostomy. ${ }^{36}$

\section{Surgical planning and position}

Following median sternotomy, the thymus was subtotally excised taking care not to expose the brachiocephalic vein. The pericardium was harvested using scissors about $1 \mathrm{~cm}$ infront of and parallel to the phrenic nerve, to avoid inadvertent cautery-induced ventricular fibrillation. Note the grossly dilated and tortuous coronary arteries. A continuous thrill is palpable at the root of the pulmonary trunk.

The operation was performed under moderately hypothermic cardiopulmonary bypass at $28^{\circ} \mathrm{C}$ using an angle venous cannula into the superior caval vein, a straight venous cannula into the inferior caval vein, and distal ascending aortic cannulation. Measures were taken to avoid excessive manipulation.

\section{Dissection of the ascending aorta and pulmonary trunk}

The pericardial reflection between the ascending and the pulmonary trunk was incised. The ascending aorta and pulmonary trunk were separated from each other. The persistent ductus arteriosus was interrupted using a liga clip (Johnson and Johnson Ltd., Ethicon, LLC, San Lorenzo, USA). The right and left pulmonary arteries were dissected and freed upto their first lobar branch.

\section{Cross-clamping of the ascending aorta and pulmonary trunk, and administration of the cardioplegia}

The aorta and pulmonary trunk were individually cross-clamped and cold hyperkalemic blood cardioplegic solution was infused simultaneously into both vessels at a pressure of $80 \mathrm{mmHg}$ for 3 minutes to achieve optimal myocardial protection. This technique avoids run-off of the cardioplegic solution from the orifice of the proximal pulmonary trunk. A small right atriotomy was done for decompression of the right heart chambers due to the infused cardioplegic solution. The left heart was vented through the right superior pulmonary vein using a left heart DLP vent catheter (Medtronic Inc., Minneapolis, MN).

\section{Transection of the distal pulmonary trunk and creation of} a vertical pulmonary arterial flap

The pulmonary trunk was opened transversely in between stay sutures just below the bifurcation and completely transected. A DLP vent catheter was inserted into the distal end of the transected pulmonary artery to prevent flooding of the surgical field. A vertical flap of the pulmonary arterial wall was fashioned for preparation of a long arterial conduit to augment the bridging aortic flap to the anomalous coronary artery. Note the orifice of the left coronary artery posterolaterally within the left posterior aortic sinus.

The vertical pulmonary arterial flap of the sinus of valsalva containing the left coronary artery at its buttom was mobilized avoiding injury to the pulmonary valve leaflets. The proximal part of the left coronary artery was mobilized over a distance of about $1 \mathrm{~cm}$.

\section{Creation of an anteriorly based aortic wall flap}

An arteriorly based, obliquely directed, rectangular flap of the aortic wall was created, approximately $10-15 \mathrm{~mm}$ above the sinutubular junction, starting from the posterior aspect towards the left lateral side and continuing to the anterior aspect of the aorta, thereby maintaining anterior continuity of the aortic flap.

While selecting the site of re-implantation of the anomalous coronary artery, precautions were taken not to damage or distort the aortic valve, to implant the anomalous left coronary artery in the appropriate sinus, to elongate the main stem of the artery by combining the obliquely positioned rectangular aortic flap with a vertical pulmonary artery flap so as to obtain a "trapdoor" effect, and avoiding narrowing, flattening, torsion, tension or saccule formation, to direct the extended main stem of the anomalous artery posterior to the pulmonary trunk in anatomical position without extrinsic compression. The neo tunnelled left coronary artery was implanted above the sinotubular junction to ensure absence of kinking and external wasting of the left coronary without any tension.

\section{Creation of an elongated neo-aortic tube by trap door technique}

The isolated segment of the pulmonary trunk containing the left coronary artery at its bottom was approximated to the neoaortic window. The right inferomedial margin of the pulmonary artery flap was sutured along the posterior lip of the neoaortic orifice. The next point of suturing starts on the left inferolateral portion of the pulmonary arterial flap. The two adjacent edges of the inferolateral margin of the pulmonary arterial flaps were sutured with each other with left coronary artery orifice at its fulcrum.

Subsequently, the redundant superior edge of the pulmonary arterial flap was folded anteriorly over the left coronary sinus. Finally, the anteriorly based, obliquely directed, small rectangular aortic flap was sutured over the residual flap to obtain a "trapdoor" effect. Thus, an obliquely positioned extended left main stem was created, maintaining a tubular confiruation with the orifice of the left coronary artery at its fulcrum. Note the absence of narrowing, flattening, kinking, wasting, tension, torsion or saccular configuration of the neoaortic site.

\section{Reconstruction of the pulmonary trunk}

The aortic cross clamp was released, restoring myocardial perfusion. The pulmonary trunk was repaired on a beating, perfused heart. The defect created in the pulmonary trunk and its sinus was repaired with an autogenous pericardial patch using 6-0 monofilament polypropylene suture. Thus, a neoaortic conduit of viable, endothelialized, antogenous arterial flaps was created for transfer of the anomalous left coronary artery with correct angling and length, avoiding injury to the aortic and pulmonary valvular apparatus, without tension, torsion, traction, or 
saccular configuration, avoiding obstruction of right ventricular outflow tract. 